
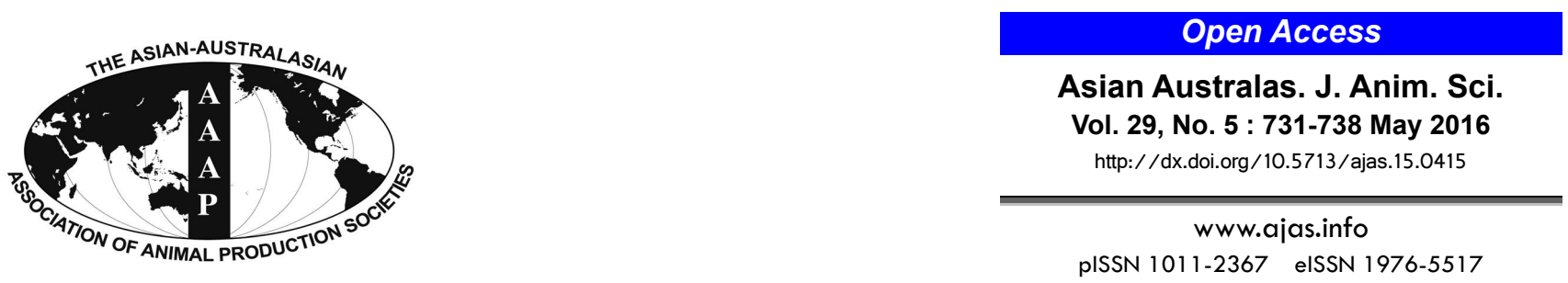

\title{
The Effects of Glucagon-like Peptide-2 on the Tight Junction and Barrier Function in IPEC-J2 Cells through Phosphatidylinositol 3-kinase-Protein Kinase B-Mammalian Target of Rapamycin Signaling Pathway
}

\author{
Changsong Yu ${ }^{1}$, Gang Jia*, Qiuhong Deng, Hua Zhao, Xiaoling Chen, Guangmang Liu, and Kangning Wang \\ Animal Nutrition Institute, Sichuan Agricultural University, Ya'an, Sichuan 625014, China
}

\begin{abstract}
Glucagon-like peptide-2 (GLP-2) is important for intestinal barrier function and regulation of tight junction (TJ) proteins, but the intracellular mechanisms of action remain undefined. The purpose of this research was to determine the protective effect of GLP-2 mediated TJ and transepithelial electrical resistance (TER) in lipopolysaccharide (LPS) stressed IPEC-J2 cells and to test the hypothesis that GLP-2 regulate TJ and TER through the phosphatidylinositol 3-kinase (PI3K)-protein kinase B (Akt)mammalian target of rapamycin (mTOR) signaling pathway in IPEC-J2 cells. Wortmannin and LY294002 are specific inhibitors of PI3K. The results showed that $100 \mu \mathrm{g} / \mathrm{mL}$ LPS stress decreased TER and TJ proteins occludin, claudin- 1 and zonula occludens protein 1 $(\mathrm{ZO}-1)$ mRNA, proteins expressions $(\mathrm{p}<0.01)$ respectively. GLP-2 $(100 \mathrm{nmol} / \mathrm{L})$ promote TER and TJ proteins occludin, claudin-1, and zo-1 mRNA, proteins expressions in LPS stressed and normal IPEC-J2 cells $(\mathrm{p}<0.01)$ respectively. In normal cells, both wortmannin and LY294002, PI3K inhibitors, prevented the mRNA and protein expressions of Akt and mTOR increase induced by GLP-2 ( $<<0.01$ ) following with the significant decreasing of occludin, claudin-1, ZO-1 mRNA and proteins expressions and TER ( $<<0.01$ ). In conclusion, these results indicated that GLP-2 can promote TJ's expression and TER in LPS stressed and normal IPEC-J2 cells and GLP-2 could regulate TJ and TER through the PI3K/Akt/mTOR pathway. (Key Words: Glucagon-like Peptide-2, IPEC-J2 Cell, Tight Junction, Transepithelial Electrical Resistance, Phosphatidylinositol 3-Kinase-Akt-mTOR Signaling Pathway)
\end{abstract}

\section{INTRODUCTION}

Intestinal epithelium not only allows selective permeability as a filter for absorption of nutrients, but also is regarded as the first line of defense against foreign antigens, such as pathogens and toxins coming from intestinal lumen (Niessen and Gottardi, 2008). Tight junction (TJ) is an important mode of cell-to-cell adhesions in the epithelial and endothelial cellular sheets, which acts as a primary barrier that prevents the diffusion of solutes through the intercellular space, especially in the intestine

\footnotetext{
* Corresponding Author: Gang Jia. Tel: +86-0835-2885005, Fax: +86-0835-2885005, E-mail: jiagang700510@163.com

${ }^{1}$ Key Laboratory of Animal Disease-Resistance Nutrition and Feed Science, Ministry of Agriculture, Ya'an, Sichuan 625014, China.

Submitted May 9, 2015; Revised Oct. 1, 2015; Accepted Nov. 11, 2015
}

(González-Mariscal et al., 2008). In animals, including pigs (Smith et al., 2010; Zhao et al., 2011), the TJ and barrier function of intestine is crucial at the time of weaning, since the $\mathrm{TJ}$ can be damaged easily by bacterial toxins (Wijtten et al., 2011; Hu et al., 2013). Lipopolysaccharide (LPS) is one of the important bacterial toxin which can induce stress ( $\mathrm{Li}$ et al., 2012; Guo et al., 2013). Therefore, improvement of $\mathrm{TJ}$ formation is considered as one of the most important steps to form an intestinal mucosal barrier against paracellular diffusion of microorganisms, toxins, and other harmful antigens across the epithelium. Glucagon-like peptide-2 (GLP-2) is an intestinotrophic growth hormone which can enhance the biological function of the intestinal. Researches showed that GLP-2 can significantly improve the villus height and weight of the small intestine in piglets and improve digestion and absorption enzyme expression in piglet intestinal (Naimi et al., 2013; Sigalet et al., 2014; 
Thymann et al., 2014). In addition, GLP-2 could recover and maintain the integrity of the intestinal mucosa epithelium barrier by increasing the expressions of zonula occludens protein 1 (ZO-1), claudin-1 and occludin in obstructive jaundice rats (Chen et al., 2008). GLP-2 could modulate the intestinal cells' proliferation and apoptosis via the phosphatidylinositol 3-kinase (PI3K)-protein kinase $\mathrm{B}(\mathrm{Akt})$-mammalian target of rapamycin (mTOR) signaling pathway (Cheeseman, 1997; Yusta et al., 2002). However, there are no studies of GLP-2 regulating the expression of TJ proteins in the IPEC-J2 cells. Therefore, the present experiments were conducted to test the hypothesis that GLP-2 could promote TJ's expression and transepithelial electrical resistance (TER) in LPS stressed and normal IPEC-J2 cells and GLP-2 could regulate TJ and TER through the PI3K-Akt-mTOR signaling pathway in IPEC-J2 cells. This research can help to understand the molecular mechanism of intestinal damage and intestinal barrier function changes and can also provide the basis for the future application of GLP-2 to improve the animal intestinal barrier function.

\section{MATERIALS AND METHODS}

The Chinese Council on Laboratory Animal Care protocols and guidelines were followed when caring for the animals.

\section{Reagents}

Dulbecco's modified Eagle medium (DMEM:Ham's F12 [1:1]), fetal bovine serum, Penicillin-Streptomycin Antibiotic Mixture and insulin-transferrin-selenium-X (ITS$\mathrm{X}$ ) were from GIBCO BRL (Gibco BRL, Gaithersburg, MD, USA). GLP-2 was from Phoenix pharmaceuticals, Belmont, CA, USA. LPS, wortmannin, LY294002, and all other chemical reagents were from Sigma Chemical (Sigma Chemical Co. St. Louis, MO, USA). Antibodies (antiglyceraldehyde-3-phosphate dehydrogenase (GAPDH), occludin, claudin-1, ZO-1, phosphorylated Akt [p-Akt], and phosphorylated mTOR [p-mTOR]) were from Santa Cruz.

\section{Cell culture}

Under sterile conditions, non-transformed IPEC-J2 cell line (College of Life Science, University of Copenhagen in Denmark) was cultured in Dulbecco's modified Eagle medium (DMEM:Ham's F-12 [1:1]) supplemented with 5\% fetal bovine serum, $1 \%$ insulin-transferrin-selenium-X (ITS$\mathrm{X})$ and antibiotics in an incubator with atmosphere of 5\% $\mathrm{CO}_{2}$ at $37^{\circ} \mathrm{C}$. The medium was replaced every $24 \mathrm{~h}$. To examine the effect of GLP-2 in the process of occludin, claudin-1, and ZO- 1 mRNA expressions, $5 \times 10^{5}$ cells were cultured on 6-well plate for 3 days until reaching the confluence. For the electrical resistance experiment, the cells were grown on $0.4-\mu \mathrm{m}$ polyester membrane trans-well (PET, $4.67 \mathrm{~cm}^{2}, 0.4 \mu \mathrm{m}$, Coning, 3450) at a density of $5 \times 10^{4}$ cells/well for 3 days. To test the effect of GLP-2 in the process of occludin, claudin-1 and ZO-1 proteins expressions, $1 \times 10^{6}$ cells were cultured on $100 \mathrm{~mm}$ culture dish for 4 days. The test time is 24 hours. The results of optimal concentration test showed that the optimal concentration of GLP-2 and LPS were $100 \mathrm{nmol} / \mathrm{L}$ and 100 $\mu \mathrm{g} / \mathrm{mL}$. The four treatments were control group, $100 \mathrm{nmol} / \mathrm{L}$ GLP-2 -treated group, $100 \mu \mathrm{g} / \mathrm{mL}$ LPS-treated group and $100 \mu \mathrm{g} / \mathrm{mL}$ LPS with $100 \mathrm{nmol} / \mathrm{L}$ GLP-2-treated group. Once the improvement effects of GLP-2 on the TJ proteins and TER in IPEC-J2 was established, wortmannin and LY294002 were used to test the molecular mechanism. The other four treatments were control group, $100 \mathrm{nmol} / \mathrm{L} \mathrm{GLP}$ 2-treated group, $100 \mathrm{nmol} / \mathrm{L}$ GLP-2 with $10 \mathrm{nmol} / \mathrm{L}$ wortmannin and $100 \mathrm{nmol} / \mathrm{L}$ GLP-2 with $10 \mu \mathrm{mol} / \mathrm{L}$ LY294002-treated group. Kinase (Akt, mTOR) assay cultivating time was 45 minutes and the others were 24 hours. The method of cell culture with the front line.

\section{Transepithelial electrical resistance measurement}

IPEC-J2 cells TER across the monolayer was measured by placing one of the electrodes in the upper well and the other in the lower well using a Millicell Electrical Resistance System with EVOM ${ }^{2}$ (15148-AB01D, World Precision Instruments, Sarasota, FL, USA) according to the manufacturer's instructions. Two readings were taken per well and averaged. The resistance from each well was subtracted by its appropriate blank, the inserts without cells to arrive at the resistance of the monolayer and then multiplied by the effective growing area to obtain TER $\left(\mathrm{Ohm} * 4.67 \mathrm{~cm}^{2}\right)$.

\section{mRNA expressions measurement}

After being washed by pre-cooling PBS 3 times, TRIZOL reagent (TaKaRa, Dalian, Liaoning, China) was added to samples of IPEC-J2. RNA extraction was performed using the chloroform/isopropyl alcohol method, followed by Qiagen RNeasy clean-up, according to the manufacturer's instructions. RNA was eluted from the column in $30 \mu \mathrm{L}$ of RNase-free water, and concentration and purity of RNA were determined using a DU-800 spectrophotometer (Beckman, Kraemer Boulevard, Brea, CA, USA). Reverse transcription polymerase chain reaction (PCR) was performed using the PrimeScript RT reagent Kit with gDNA Eraser (Perfect Real Time) (Code No. RR047A; TaKaRa, China). Reaction conditions and PCR program followed the manufacturer's instructions. Different porcine gene specific primers (Invitrogen, Carlsbad, CA, USA) were used (Table 1). Primer pairs were designed using Primer3 program based on NCBI porcine sequences. Real time PCR (RT-PCR) was performed using a CFX-96 real 
Table 1. Gene primers sequence and annealing temperature

\begin{tabular}{|c|c|c|c|c|}
\hline Gene & GeneBank & $\left(5^{\prime} \rightarrow 3^{\prime}\right)$ & $\left(\mathrm{Tm},{ }^{\circ} \mathrm{C}\right)$ & (bp) \\
\hline \multirow[t]{2}{*}{ GAPDH } & NM_001206359.1 & Forward: GATGGTGAAGGTCGGAGTGAAC & 60.9 & 153 \\
\hline & & Reversed: TGGGTGGAATCATACTGGAACA & & \\
\hline \multirow[t]{2}{*}{ Occludin } & NM_001163647.2 & Forward: ACGAGCAGCAAAGGGATTCTTC & 61.2 & 152 \\
\hline & & Reversed: TCACACCCAGGATAGCACTCATT & & \\
\hline \multirow[t]{2}{*}{ Claudin-1 } & NM_001244539.1 & Forward: TGCCTCAGTGGAAGATTTACTCC & 60.1 & 147 \\
\hline & & Reversed: TGGTGTTCAGATTCAGCAAGGA & & \\
\hline \multirow[t]{2}{*}{ ZO-1 } & XM_005659811.1 & Forward: AGTTTGATAGTGGCGTTGACAC & 60.0 & 106 \\
\hline & & Reversed: GCTGAAGGACTCACAGGAACA & & \\
\hline \multirow[t]{2}{*}{ Akt } & NM_001159776.1 & Forward: GCACAAACGAGGCGAGTA & 61.4 & 195 \\
\hline & & Reversed: CAGCGGATGATGAAGGTGTT & & \\
\hline \multirow[t]{2}{*}{ m-TOR } & XM_003127584.4 & Forward: GGATGCTGGTGTCCTTTGTGA & 60.09 & 102 \\
\hline & & Reversed: TGCTCTGGATGGAGGTGTTCAT & & \\
\hline
\end{tabular}

Tm, temperature; GAPDH, glyceraldehyde-3-phosphate dehydrogenase; ZO-1, zonula occludens protein 1; m-TOR, mammalian target of rapamycin.

time PCR system (Bio-Rad, Alfred Nobel Drive, Hercules, CA, USA) with the SYBR Premix Ex Taq TM II (Tli RNaseH Plus) (Code No. RR820A; TaKaRa, China). cDNA $(1 \mu \mathrm{L})$ was added in a $25 \mu \mathrm{L}$ reaction mixture which contained 12.5 $\mu \mathrm{L}$ SYBR Premix Ex Taq II (Tli RNaseH Plus) $(2 \times), 10 \mu \mathrm{M}$ each primer, $2 \mu \mathrm{L}$ cDNA and $8.5 \mu \mathrm{L}$ $\mathrm{dH} 2 \mathrm{O}$. The program setting was $30 \mathrm{~s}$ at $95^{\circ} \mathrm{C}$ and then 40 cycles of $95^{\circ} \mathrm{C}$ for $5 \mathrm{~s}, 60^{\circ} \mathrm{C}$ to $62^{\circ} \mathrm{C}$ (depending on the primers used) for $30 \mathrm{~s}$, and $72^{\circ} \mathrm{C}$ for $30 \mathrm{~s}$. On the completion of amplification, a melting curve was produced by holding the reaction mixture at $65^{\circ} \mathrm{C}$ to $95^{\circ} \mathrm{C}$ with a heating rate of $0.1{ }^{\circ} \mathrm{C}$ per second and a continuous fluorescence measurement and finally a cooling step to $40^{\circ} \mathrm{C}$. The housekeeping gene encoding GAPDH was used as an internal control. The analysis consisted of four independent experiments. Each experimental sample was assayed using four replicates for each primer. The relative levels of the mRNA of the genes of interest were normalized to the GAPDH mRNA and were determined using a modified $2^{-\Delta \Delta C t}$ method (Pfaffl, 2001).

\section{Protein preparation and western blotting}

IPEC-J2 cells were washed with ice-cold PBS and immediately lysed in lysis buffer $(20 \mathrm{mM}$ Tris- $\mathrm{HCl}, 150$ $\mathrm{mM} \mathrm{NaCl}, 1 \mathrm{mM}$ Ethylenediaminetetraacetic acid (EDTA), $1 \%$ Triton X-100) followed by quantitation of protein using Micro BCA kit (Thermo, Rockford, IL, USA). After the protein concentration of supernatant fractions was quantized by a standard bicinchoninic acid (BCA) protein assay kit (Bio-Rad, USA), equal amount of proteins for each sample was loaded in 10\% Tris-glycine polyacrylamide gels and electrophoresed. Then, the proteins were transferred onto a polyvinylidene difluoride microporous membrane (Millpore, Bedford, MA, USA) for $2 \mathrm{~h}$ at $4^{\circ} \mathrm{C}$ and blocked with $5 \%$ skim milk in TBS-T $(20 \mathrm{mM}$ Tris $\mathrm{HCl}, 100 \mathrm{mM} \mathrm{NaCl}$, $0.05 \%$ Tween 20) for $90 \mathrm{~min}$ and then incubated sequentially with primary antibody overnight. The primary antibodies being used were: Polyclonal anti-claudin-1 (Santa Cruz Biotechnology Inc., Dallas, TX, USA) diluted 1:500, anti-occludin (Santa Cruz Biotechnology Inc., USA) diluted 1:450, anti-ZO-1 (Santa Cruz Biotechnology Inc., USA) diluted 1:400, anti-p-Akt $\left(\mathrm{Ser}^{473}\right)$ (Santa Cruz Biotechnology Inc., USA) diluted 1:1,000, anti-pmTOR $\left(\mathrm{Ser}^{2448}\right)$ (Santa Cruz Biotechnology Inc., USA) diluted 1:2,000 and anti-GAPDH (Cell Signaling Technology Inc., Danvers, MA, USA) diluted 1:2,000. Subsequently, the membrane was washed and incubated with IgG-HRP (Santa Cruz Biotechnology Inc., USA) (diluted at 1:5,000) for $1 \mathrm{~h}$. The target proteins were visualized by enhanced chemiluminescence system (GE Healthcare, Waukesha, WI, USA) followed by analysis using Gel Doc TM XR (Bio-rad, USA). Intensity of the blotting was quantified using qualityone software.

\section{Statistical analysis}

Sigmastat statistical software (SPSS17.0) was used to analyze densitometry results of TER, mRNA and protein relative expression levels for Western blots. All data were reported as means \pm standard deviation from 3 independent experiments. One-way analysis of variance (ANOVA) was used to determine whether a significant difference was present among all treatment groups. Additionally, Bonferroni $t$ tests were performed for comparisons when the ANOVA was very significant at $p<0.01$ (Agresti and Kateri, 2011).

\section{RESULTS}

\section{Effects on transepithelial electrical resistance}

Compared with the control group, $100 \mu \mathrm{g} / \mathrm{mL}$ LPS significantly decreased the IPEC-J2 cell's TER 92.4\% $(\mathrm{p}<0.01)$. IPEC-J2 cell's TER significantly increased by 


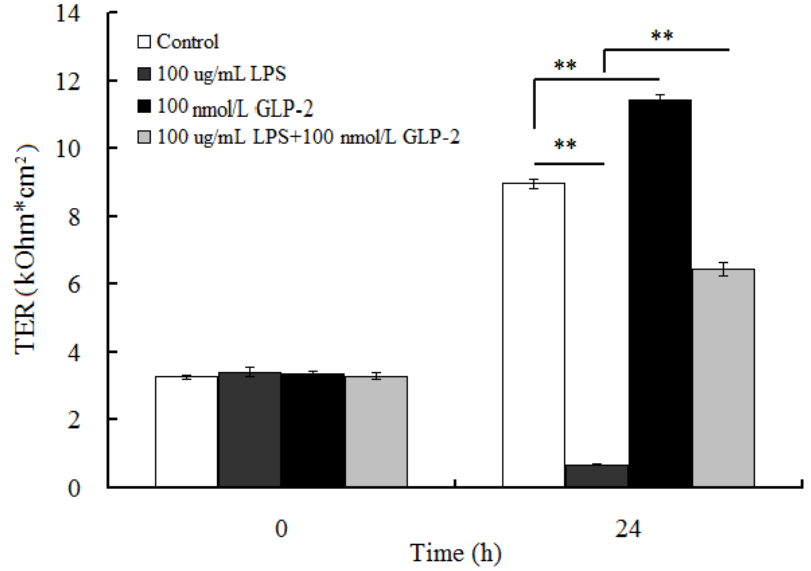

Figure 1. Effects of glucagon-like peptide-2 (GLP-2) and lipopolysaccharide (LPS) on the trans-epithelial resistance (TER) IPEC-J2 cells.

$27.2 \%$ in $100 \mathrm{nmol} / \mathrm{L}$ GLP-2-treated group $(\mathrm{p}<0.01)$. GLP-2 inhibited the damnification of TER caused by LPS stress and maintained the barrier function of IPEC-J2 cells (Figure 1).

As shown in Figure 2, in comparison with the control group, GLP-2 $(100 \mathrm{nmol} / \mathrm{L})$ increased the TER $(\mathrm{p}<0.01)$. But when wortmannin $(10 \mathrm{nmol} / \mathrm{L})$ was added into the medium, the TER significantly decreased by $5.4 \%(\mathrm{p}<0.01)$ and decreased by $10.3 \%$ in the $100 \mathrm{nmol} / \mathrm{L}$ GLP- 2 with 10 $\mu \mathrm{mol} / \mathrm{L}$ LY294002-treated group $(\mathrm{p}<0.01)$.

\section{Effects on mRNA expressions of tight junction and signaling molecules}

The results showed that compared with the control, the expressions of occludin, claudin-1 and ZO-1 mRNA decreased by $46 \%, 57 \%$, and $34 \%$ respectively in the 100 $\mu \mathrm{g} / \mathrm{mL}$ LPS -treated group $(\mathrm{p}<0.01)$ and increased by $148 \%$, $261 \%$, and $54 \%$ respectively in the $100 \mathrm{nmol} / \mathrm{L}$ GLP-2treated group $(\mathrm{p}<0.01)$. Compared with the $100 \mu \mathrm{g} / \mathrm{mL}$ LPS-treated group, $100 \mu \mathrm{g} / \mathrm{mL}$ LPS with $100 \mathrm{nmol} / \mathrm{L}$ GLP-2

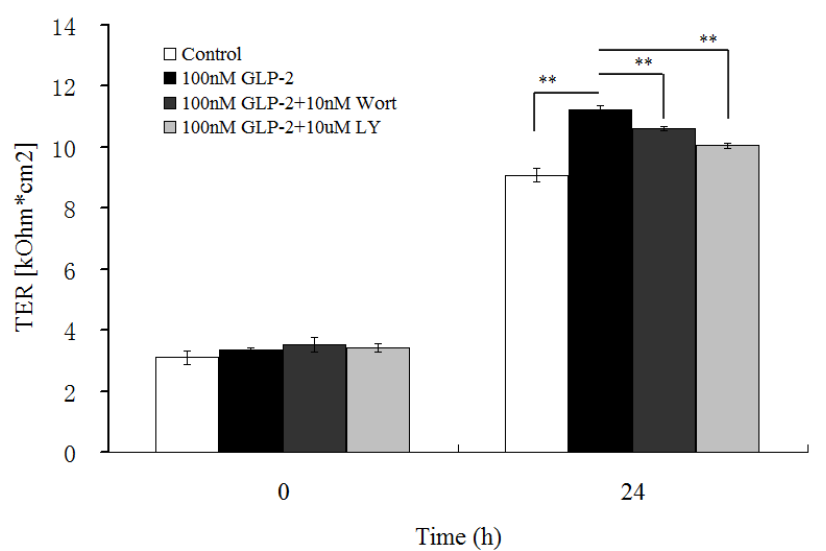

Figure 2. Effects of signaling inhibitors on trans-epithelial resistance (TER) in IPEC-J2 cells, in the presence of $100 \mathrm{nmol} / \mathrm{L}$ glucagon-like peptide-2 (GLP-2).
Table 2. Effects of GLP-2 and LPS on the mRNA relative expression of occludin, claudin-1 and ZO-1 in IPEC-J2 cells

\begin{tabular}{lcccc}
\hline & \multicolumn{4}{c}{ Treatment groups } \\
\cline { 2 - 5 } & Control & LPS & GLP-2 & LPS+GLP-2 \\
\hline Occludin & $1.00 \pm 0.04$ & $0.54 \pm 0.06^{* *}$ & $2.48 \pm 0.07^{* *}$ & $0.79 \pm 0.08^{* *}$ \\
Claudin-1 & $1.00 \pm 0.02$ & $0.43 \pm 0.04^{* *}$ & $3.61 \pm 0.08^{* *}$ & $0.71 \pm 0.10^{* *}$ \\
ZO-1 & $1.00 \pm 0.03$ & $0.66 \pm 0.05^{* *}$ & $1.54 \pm 0.05^{* *}$ & $0.86 \pm 0.04^{* *}$
\end{tabular}

GLP-2, glucagon-like peptide-2; LPS, lipopolysaccharide; ZO-1, zonula occludens protein 1 .

** Significant differences.

significantly increased occludin, claudin- 1 , and ZO-1 mRNA expression $(\mathrm{p}<0.01)$ respectively by $46.3 \%, 65.1 \%$, and $30.3 \%$ (Table 2 ).

As depicted in Table 3, compared with the control, the addition of GLP-2 $(100 \mathrm{nmol} / \mathrm{L})$ increased the expressions of Akt, mTOR, occluding, claudin, and ZO-1 mRNA $(\mathrm{p}<0.01)$ while these effects were blocked when wortmannin $(10 \mathrm{nmol} / \mathrm{L})$ and LY294002 $(10 \mu \mathrm{mol} / \mathrm{L})$ was simultaneously added into the medium with GLP-2. Wortmannin and LY294002 inhibited GLP-2-induced upregulation of occluding, claudin and ZO-1 mRNA expressions $(\mathrm{p}<0.05)$. Compared with the $100 \mathrm{nmol} / \mathrm{L}$ GLP2-treated group, the mRNA expressions of Akt, mTOR, occluding, claudin and ZO-1 decreased by $46.9 \%, 50.5 \%$, $38.1 \%, 49.6 \%$, and $18.9 \%$ respectively in the $100 \mathrm{nmol} / \mathrm{L}$ GLP-2 with $10 \mathrm{nmol} / \mathrm{L}$ wortmannin-treated group $(\mathrm{p}<0.01)$ and decreased $67.2 \%, 70.8 \%, 49.6 \%, 60.9 \%$, and $25.8 \%$ respectively in the $100 \mathrm{nmol} / \mathrm{L}$ GLP-2 with $10 \mu \mathrm{mol} / \mathrm{L}$ LY294002-treated group $(\mathrm{p}<0.01)$.

\section{Effects on proteins expressions of tight junction and signaling molecules}

In comparison with the control group, the protein relative abundance of occluding, claudin and ZO-1 increased by $35 \%, 39 \%$, and $62 \%$ respectively $(\mathrm{p}<0.01)$ in the $100 \mathrm{nmol} / \mathrm{L}$ GLP-2-treated group and decreased by $76.5 \%, 81.7 \%$, and $78.8 \%$ respectively $(\mathrm{p}<0.01)$ in the 100 $\mu \mathrm{g} / \mathrm{mL}$ LPS-treated group. However, compared with the LPS-treated group, $100 \mu \mathrm{g} / \mathrm{mL}$ LPS with $100 \mathrm{nmol} / \mathrm{L}$ GLP-2

Table 3. Effects of signaling inhibitors on the relative mRNA expression of Akt, mTOR, occludin, claudin-1, and ZO-1 in IPEC-J2 cells, in the presence of $100 \mathrm{nmol} / \mathrm{L}$ GLP-2

\begin{tabular}{lcccc}
\hline & \multicolumn{4}{c}{ Treatment groups } \\
\cline { 2 - 5 } & Control & GLP-2 & GLP-2+Wort & GLP-2+LY \\
\hline Akt & $1.00 \pm 0.03$ & $4.78 \pm 0.19^{* *}$ & $2.54 \pm 0.08^{* *}$ & $1.57 \pm 0.06^{* *}$ \\
mTOR & $1.00 \pm 0.05$ & $5.90 \pm 0.11^{* *}$ & $2.92 \pm 0.04^{* *}$ & $1.72 \pm 0.03^{* *}$ \\
Occludin & $1.00 \pm 0.04$ & $2.60 \pm 0.08^{* *}$ & $1.61 \pm 0.05^{* *}$ & $1.31 \pm 0.04^{* *}$ \\
Claudin-1 & $1.00 \pm 0.06$ & $3.71 \pm 0.06^{* *}$ & $1.87 \pm 0.05^{* *}$ & $1.45 \pm 0.05^{* *}$ \\
ZO-1 & $1.00 \pm 0.05$ & $1.59 \pm 0.07^{* *}$ & $1.29 \pm 0.07^{* *}$ & $1.18 \pm 0.08^{* *}$ \\
\hline
\end{tabular}

mTOR, mammalian target of rapamycin; ZO-1, zonula occludens protein 1; GLP-2, glucagon-like peptide-2; LY, LY294002.

** Significant differences. 
significantly increased occludin, claudin-1 and ZO-1 protein expression $(\mathrm{p}<0.01)$ respectively by $183 \%, 300 \%$, and $231.8 \%$ (Figure 3 ).

As shown in Figure 4, in comparison with the control group, GLP-2 (100 nmol/L) increased the abundance of all protein $(\mathrm{p}<0.01)$. But when wortmannin $(10 \mathrm{nmol} / \mathrm{L})$ was added into the medium, the relative abundance of $\mathrm{p}$-Akt, $\mathrm{p}$ mTOR, occluding, claudin, and ZO-1 significantly decreased by $15.5 \%, 15.4 \%, 10.8 \%, 14.2 \%$, and $27.6 \%$ respectively $(\mathrm{p}<0.01)$ and decreased by $24.2 \%, 22.5 \%$, $13.7 \%, 16.3 \%$, and $31.9 \%$ respectively in the $100 \mathrm{nmol} / \mathrm{L}$ GLP-2 with $10 \mu \mathrm{mol} / \mathrm{L}$ LY294002-treated group $(\mathrm{p}<0.01)$.

\section{DISCUSSION}

GLP-2 is a 33-amino acid intesti-notrophic hormone derived from posttranslational processing of proglucagon in the enteroendocrine $\mathrm{L}$ cells of the ileum and colon (Cameron and Perdue, 2005). As a physiological regulator of mucosal epithelial homeostasis, GLP-2 plays an important role in intestinal permeability. Dong et al. (2013) found that GLP-2 can significantly improve the expression of occludin and Claudin-3, 7 mRNA and proteins in the mouse jejunum. Moran et al. (2012) found that GLP2 can not only significantly increase the expression of occludin and ZO-1 proteins in Caco- 2 cell but also can effectively inhibit the reduction of occludin and ZO-1 expression caused by tumor necrosis factor $\alpha$ (TNF- $\alpha$ ) stress. The above results show that, GLP-2 can effectively promote the expression of $\mathrm{TJ}$ in intestinal epithelial cells and enhance intestinal barrier function. The study on piglet jejunum cell model results show that GLP-2 can significantly improve the expressions of occludin, Claudin1 and ZO-1 in normal IPEC-J2 cells. In addition, GLP-2 can also inhibit TJ expression decreasing caused by LPS stress in IPEC-J2 cells. The results suggest that, GLP-2 can promote healthy intestinal epithelial $\mathrm{TJ} \mathrm{mRNA}$ and protein expressions and can effectively inhibit of the immune stress caused by LPS. GLP-2 may be used as a promising alleviate nutrition relieves stress of weaned piglets.

The results of study on LPS effecting on IPEC-J2 cells show that LPS can increase cell inflammation factor and induce cells inflammatory reaction (Razzuoli et al., 2013; Paszti-Gere et al., 2014). Our study found when IPEC$\mathrm{J} 2$ cells were stressed by LPS, the expression level of TJ proteins occludin, claudin-1, and ZO-1 mRNA and proteins significantly decreased, which indicated that LPS could cause serious damage to IPEC-J2 cells' TJ. Hou et al. (2012) study found that LPS could significantly reduce expressions of claudin-1 and occludin in weaned piglets' jejunum and ileum epithelial cells and can reduce the content of RNA and total protein in jejunum. In addition, Liu et al. (2008) found that, LPS could change intestinal morphology and increase intestinal epithelial permeability

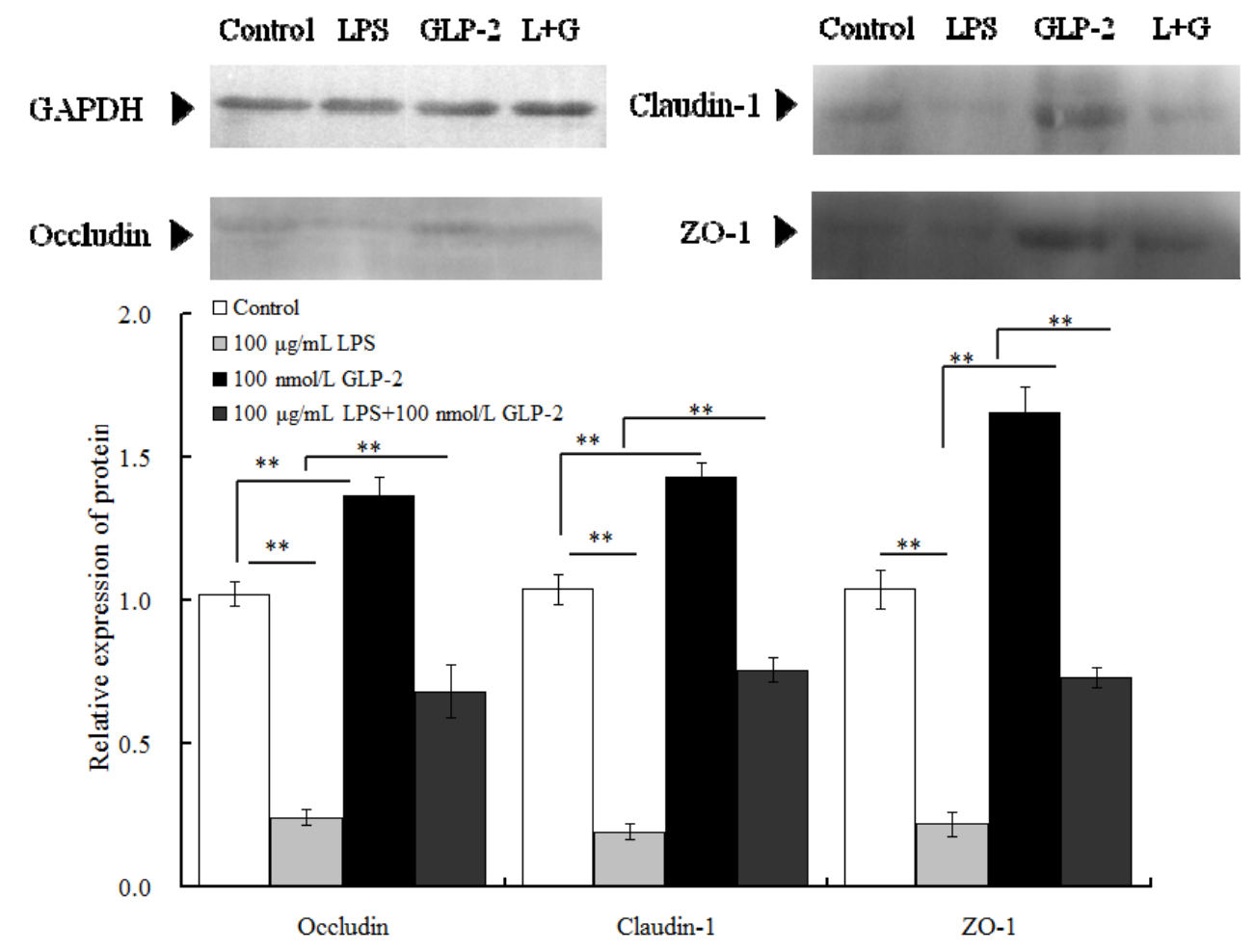

Figure 3. Effects of glucagon-like peptide-2 (GLP-2) and lipopolysaccharide (LPS) on the protein relative expression of occludin, claudin-1, and zonula occludens protein 1 (ZO-1) in IPEC-J2 cells. 

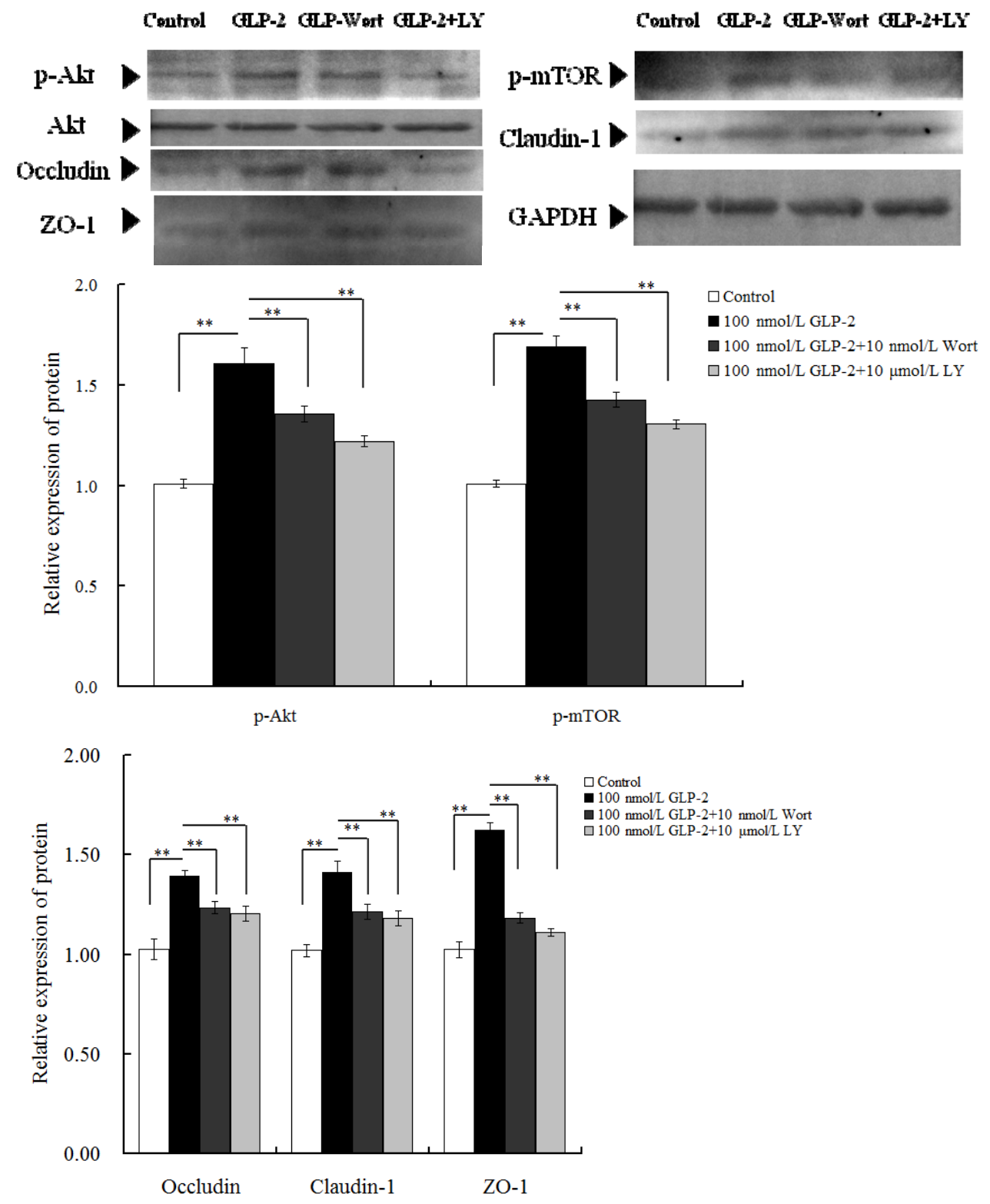

Figure 4. Effects of signaling inhibitors on the relative protein expression of, p-Akt, p-mTOR, occludin, claudin-1, and zonula occludens protein 1 (ZO-1) in IPEC-J2 cells, in the presence of $100 \mathrm{nmol} / \mathrm{L}$ glucagon-like peptide-2 (GLP-2).

and destroy the intestinal barrier function. We also found that the expression of $100 \mu \mathrm{g} / \mathrm{mL}$ LPS could not completely destroy IPEC-J2 cell TJ protein and the cell barrier function. The results were in accord with the experimental results reported by Geens and Niewold (2010), and Arce et al. (2010), indicating that IPEC-J2 cells have a certain resistance to LPS immune stress and can protect the cell structure and function from being completely damaged by LPS immune stress. The early research showed that GLP-2 can increase the content of sodium dependent glucose transporter protein in mouse jejunal brush border membrane and can promote the growth and development of jejunum. The further results showed that GLP-2 promote cell growth through PI3K when PI3K specific inhibitor Wortmannin was used (Cheeseman et al., 1997). Yusta et al. (2002) found that GLP-2 can promote baby hamster kidney epithelial cell growth though the PI3K-Akt signal pathway when use LY294002 as PI3K specific inhibitor. Shi et al. (2011) found that GLP-2 can promote protein synthesize in epithelial cells through PI3K-Akt-mTOR signal pathway and this result determine the important role of $\mathrm{mTOR}$ in the process that GLP-2 promote protein expression in epithelial cells. However, there were articles reporting that GLP-2 didn't modulate the mouse or human colon cancer cell growth and survival through the PI3K-Akt-mTOR signal transduction pathway (Koehler et al., 2008). The study suggests that GLP-2 regulate the growth, intracellular protein expression through the cell regulation of PI3K-Akt- 
mTOR signal transduction pathway is not in all cells. Therefore, it is significant to illustrate the role of PI3K-AktmTOR signal transduction pathway in the GLP-2 regulation of TJ in piglets jejunum epithelial cells. This experiment results showed that GLP-2 can significantly increase the expression of occludin, claudin-1 protein, and ZO-1 through PI3K-Akt-mTOR signal transduction pathway. The results was in accord with Shi et al. (2013), suggesting that PI3KAkt-mTOR signal transduction pathway is one of important signaling pathways that GLP-2 regulate cell TJ and barrier function.

\section{CONCLUSION}

In summary, the results showed that LPS stress significantly reduced expression of TJ in IPEC-J2 cells and damage the barrier function of IPEC-J2 cells. GLP-2 can increase TER on the LPS stressed IPEC-J2 cells and enhance the barrier function, which are associated with the functions of promoting the mRNA and proteins expressions of the key proteins of TJ (occludin, claudin-1, ZO-1). GLP2 may modulate TJ's expression and barrier function through PI3K-Akt-mTOR signal transduction pathway in IPEC-J2 cells.

\section{CONFLICT OF INTEREST}

We certify that there is no conflict of interest with any financial organization regarding the material discussed in the manuscript.

\section{ACKNOWLEDGMENTS}

This research was supported by Sichuan Provincial Education Department of Outstanding Academic and Technical Youth Leadership Fund (2010JQ0043), China and Doctoral Fund of Ministry of Education (2015103110011), China.

\section{REFERENCES}

Agresti, A. and M. Kateri. 2011. Categoricaldata analysis. Springer Berlin Heidelberg, Berlin, Germany.

Arce, C., M. Ramirez-Boo, C. Lucena, and J. J. Garrido. 2010. Innate immune activation of swine intestinal epithelial cell lines (IPEC-J2 and IPI-2I) in response to LPS from Salmonella typhimurium. Comp. Immunol. Microbiol. Dis. 33:161-174.

Cameron, H. L. and M. H. Perdue. 2005. Stress impairs murine intestinal barrier function: Improvement by glucagon-like peptide-2. J. Pharmacol. Exp. Ther. 314:214-220.

Cheeseman, C. I. 1997. Upregulation of SGLT-1 transport activity in rat jejunum induced by GLP-2 infusion in vivo. Am. J. Physiol. Regul. Integr. Comp. Physiol. 273:R1965-R1971.

Chen, Z. Y., X. S. Feng, and P. Yang. 2008. Effect of glucagon-like peptide- 2 on modulation of intestinal epithelium tight junction in rats with obstructive jaundice. Chin. J. Gen. Surg. 17:760763.

Dong, C. X., W. Zhao, C. Solomon, K. J. Rowland, C. Ackerley, S. Robine, and P. L. Brubaker. 2013. The intestinal epithelial insulin-like growth factor-1 receptor links glucagon-like peptide-2 action to gut barrier function. Endocrinology 155: 370-379.

Geens, M. M. and T. A. Niewold. 2010. Preliminary characterization of the transcriptional response of the porcine intestinal cell line IPEC-J2 to enterotoxigenic Escherichia coli, Escherichia coli, and E. coli lipopolysaccharide. Comp. Funct. Genomics 2010: Article ID 469583.

Guo, S., R. Al-Sadi, H. M. Said, and T. Y. Ma. 2013. Lipopolysaccharide causes an increase in intestinal tight junction permeability in vitro and in vivo by inducing enterocyte membrane expression and localization of TLR-4 and CD14. Am. J. Pathol. 182:375-387.

González-Mariscal, L., R. Tapia, and D. Chamorro. 2008. Crosstalk of tight junction components with signaling pathways. Biochem. Biophys. Acta-Biomembranes 1778:729756.

Hu, C. H., K. Xiao, Z. S. Luan, and J. Song. 2013. Early weaning increases intestinal permeability, alters expression of cytokine and tight junction proteins, and activates mitogen-activated protein kinases in pigs. J. Anim. Sci. 91:1094-1101.

Hou, Y., L. Wang, W. Zhang, Z. Yang, B. Ding, H. Zhu, and G. Wu. 2012. Protective effects of $\mathrm{N}$-acetylcysteine on intestinal functions of piglets challenged with lipopolysaccharide. Amino Acids 43:1233-1242.

Koehler, J. A., W. Harper, M. Barnard, B. Yusta, and D. J. Drucker. 2008. Glucagon-like peptide-2 does not modify the growth or survival of murine or human intestinal tumor cells. Cancer Res. 68:7897-7904.

Li. Q., Y. Liu, Z. Che, H. Zhu, G. Meng, Y. Hou, and F. Chen. 2012. Dietary L-arginine supplementation alleviates liver injury caused by Escherichia coli LPS in weaned pigs. Innate Immun. 18:804-814.

Liu, Y., J. Huang, Y. Hou, H. Zhu, S. Zhao, B. Ding, and W. Fan. 2008. Dietary arginine supplementation alleviates intestinal mucosal disruption induced by Escherichia coli lipopolysaccharide in weaned pigs. Br. J. Nutr. 100:552-560.

Moran, G. W., C. O'Neill, and J. T. McLaughlin. 2012. GLP-2 enhances barrier formation and attenuates TNF $\alpha$-induced changes in a Caco-2 cell model of the intestinal barrier. Regul. Pept. 178:95-101.

Naimi, R. M., K. B. Madsen, C. Askov-Hansen, C. F. Brandt, B. Hartmann, J. J. Holst, and P. B. Jeppesen. 2013. A doseequivalent comparison of the effects of continuous subcutaneous glucagon-like peptide 2 (GLP-2) infusions versus meal related GLP-2 injections in the treatment of short bowel syndrome (SBS) patients. Regul. Pept. 184:47-53.

Niessen, C. M. and C. J. Gottardi. 2008. Molecular components of the adherens junction. Biochem. Biophys. Acta-Biomembranes 1778:562-571.

Paszti-Gere, E., G. Matis, O. Farkas, A. Kulcsar, O. Palocz, G. Csiko, and P. Galfi. 2014. The effects of intestinal LPS exposure on inflammatory responses in a porcine enterohepatic 
co-culture system. Inflammation 37:247-260.

Pfaffl, M. W. 2001. A new mathematical model for relative quantification in real time RT-PCR. Nucl. Acids Res. 29:e45.

Razzuoli, E., R. Villa, and M. Amadori. 2013. IPEC-J2 cells as reporter system of the anti-inflammatory control actions of interferon-alpha. J. Interferon. Cytokine Res. 33:597-605.

Smith, F., J. E. Clark, B. L. Overman, C. C. Tozel, J. H. Huang, J. E. Rivier, and A. J. Moeser. 2010. Early weaning stress impairs development of mucosal barrier function in the porcine intestine. Am. J. Physiol. Gastrointest. Liver Physiol. 298:G352-G363.

Sigalet, D. L., E. de Heuvel, L. Wallace, E. Bulloch, J. Turner, P. Nation, and J. J. Holst. 2014. Effects of chronic glucagon-like peptide- 2 therapy during weaning in neonatal pigs. Regul. Pept. 188:70-80.

Shi, X., F. Zhou, X. Li, B. Chang, D. Li, Y. Wang, and X. Guan. 2013. Central GLP-2 enhances hepatic insulin sensitivity via activating PI3K signaling in POMC neurons. Cell Metabol. 18: 86-98.
Shi, X., X. Li, Y. Wang, K. Zhang, F. Zhou, L. Chan, and X. Guan. 2011. Glucagon-like peptide-2-stimulated protein synthesis through the PI 3-kinase-dependent Akt-mTOR signaling pathway. Am. J. Physiol. Endocrinol. Metab. 300:E554-E563.

Thymann, T., I. Le Huërou-Luron, Y. M. Petersen, M. S. Hedemann, J. Elinf, B. B. Jensen, and P. T. Sangild. 2014. Glucagon-like peptide 2 treatment may improve intestinal adaptation during weaning. J. Anim. Sci. 92:2070-2079.

Wijtten, P. J., J. van der Meulen, and M. W. Verstegen. 2011. Intestinal barrier function and absorption in pigs after weaning: A review. Br. J. Nutr. 105:967-981.

Yusta, B., J. Estall, and D. J. Drucker. 2002. Glucagon-like peptide-2 receptor activation engages bad and glycogen synthase kinase-3 in a protein kinase A-dependent manner and prevents apoptosis following inhibition of phosphatidylinositol 3-kinase. J. Biol. Chem. 27:24896-24906.

Zhao, Y., G. Qin, Z. Sun, D. Che, N. Bao, and X. Zhang. 2011. Effects of soybean agglutinin on intestinal barrier permeability and tight junction protein expression in weaned piglets. Int. J. Mol. Sci. 12:8502-8512. 